\title{
High 5s initiative: implementation of medication reconciliation in France a 5 years experimentation
}

\author{
É. Dufay ${ }^{{ }^{*}}$, S. Doerper ${ }^{1}$, B. Michel ${ }^{2}$, C. Roux Marson ${ }^{3}$, A. Grain ${ }^{4}$, A. M. Liebbe ${ }^{5}$, K. Long ${ }^{6}$, N. Tournade ${ }^{7}$, B. Allenet ${ }^{8}$, \\ D. Breilh ${ }^{9}$, I. Alquier ${ }^{10}$ and May L. Michelangeli ${ }^{10}$
}

\begin{abstract}
The International High 5s Project was developed by the World Health Organisation to address major concerns about patient safety. The Standard Operating Protocol (SOP) for ensuring medication accuracy during transitional care is a part of the High 5s Project. The impetus behind medication reconciliation is to prevent adverse drug events by decreasing the rate of undocumented discrepancies as patients move from one level of care to another. The aim of this article is to present the results of the French experimentation. During 5 years, 9 healthcare facilities implemented the SOP Medication Reconciliation at admission. Eligible inpatients included patients aged over 65 years admitted through the Emergency Department. The indicator for the rate of undocumented discrepancies is assessed as the time required per reconciliation.

From 2010 to 2014, 27447 inpatients were reconciled (14.0\% of eligible patients for reconciliation). The mean of undocumented discrepancies per patient was 1.7 (46 188). Among the undocumented discrepancies, unintentional medication errors which are at the same time non documented and non intentional stand out (however one health facility used a different methodology): the mean of intercepted and corrected medication errors was 0.9 (21 320 for 22 863 patients). All were resolved during the collaborative exchange between pharmacists and physicians. The mean time to perform the reconciliation was about 31.8 min (IC 95\% [31.6; 32.0]).

In France the medication reconciliation process has demonstrated to be a powerful strategy to reduce undocumented discrepancies and in particular medication errors. The next steps should focus on extending the process either to all stages of the transitional care or to different types of patients (other than Emergency room patients) or health sectors.
\end{abstract}

Keywords: High 5s, Medication reconciliation, Inpatients, Discrepancy, Medication error

\section{Initiative of the High 5s}

The High 5 s initiative is an international cooperation programme launched in 2006 by the World Alliance for Patient Safety by the WHO. Within the context of "Action on Patient Safety", the initiative has been built on the basis of a partnership with the WHO, the Commonwealth Fund and the Joint Commission International. The key element of High $5 \mathrm{~s}$ is to implement Standard Operating Protocols (SOP) within health facilities irrespective of the type of health system and cultural context in order to promote patients' safety widely and efficiently [1].

\footnotetext{
* Correspondence: edufay@ch-luneville.fr

1Centre hospitalier de Lunéville, BP 30 206, 54301 Lunéville cedex, France Full list of author information is available at the end of the article

In 2009, in collaboration with four other countries Germany, Australia, USA and the Netherlands, France has joined one of the High $5 \mathrm{~s}$ project named SOP on Medication Reconciliation (SOP Med'Rec) [2]. The Haute Autorité de Santé has coordinated this project in France; the target was to reinforce the comprehensiveness and accuracy of prescriptions during the transitional stage of the patients' care to improve the patients' safety.

\section{Description of the patient safety problem}

Adverse drug events are a leading cause of injury and death within healthcare systems. Communication's failures between the different levels of care are a significant factor in their occurrence [3, 4]. When transitioning between levels of care, patients' prescription 
information is not always transferred to all care providers in a timely manner. Consequently, the patients may not receive the most appropriate regimen for their condition and circumstances [5, 6]. The impetus behind medication reconciliation is the prevention of adverse drug events by decreasing the rate of undocumented discrepancies as patients move from one level of care to another. Undocumented discrepancies comprise intentional discrepancies and medication errors (unintentional discrepancies). All medication errors are not fatal. However, five independent studies found that 5.6, 5.7, 6.3, 6.4 and $11,7 \%$ of the errors intercepted through the reconciliation could have had major consequences either critical or catastrophic for the patients [7-11].

\section{Description of the SOP Med'Rec}

A SOP is a standardised organisational practice developed on the basis of research work and on the expertise of international specialists. It is a body of tangible instructions allowing for the standardised (regular and measurable) implementation by professionals of a defined process to follow the patient.

The SOP Med'Rec of High 5s includes a defined and standardised process, an implementation plan and an evaluation plan [2]. It focuses on prevention and interception of medication errors which could happen during the transition point that is the admission of a patient to a health facility. Medication errors are errors by omission or by addition as well as errors of medication, dosage, type of treatment and time of administration. The SOP Med'Rec targets all the medication taken or to be regularly taken by the patients before their hospitalisation, whether they were prescribed by a doctor or taken via self-medication.

The medication reconciliation is a formal process of 4 steps:

- Obtaining complete and accurate information about the patient's current medication taken at home;

- Analysing the collected data to establish the best possible medication list;

- Validating the medication list to attest its reliability and to allow its dissemination;

- Sharing and using this medication list when writing prescriptions at admission or using it to compare it against the patients' prescriptions in order to bring any undocumented discrepancies to the attention of the prescriber. Either the intentional discrepancies are documented or the medication errors are corrected by the prescriber. All discrepancies and any resulting changes in orders have to be documented.

\section{Description and results of the French experimentation}

To undertake this project over a 5 years period (2010 2014), 9 health facilities have volunteered: Centre hospitalier universitaire de Bordeaux, Centre hospitalier de Compiègne Noyon, Centre hospitalier universitaire de Grenoble, Centre hospitalier de Lunéville, Clinique de la Croix blanche de Moutier Rozeille, Centre hospitalier universitaire de Nîmes, Hôpital de Bichat-Claude Bernard de l'Assistance publique des hôpitaux de Paris, Centre hospitalier de Saint Marcellin, Hôpitaux universitaires de Strasbourg. Eligible patients to the SOP Med'Rec were patients over 65 years old, admitted for short hospitalisation via the Emergency Department. The pharmacists were involved in gathering and validating the data for the measuring performance of the reconciliation rates and discrepancies but not of the adverse drug events. Monthly data for each health facility, as well as their annual report are available of the Haute Autorite de Sante website [11].

From 2010 to 2014, 27447 inpatients were reconciled (14.0\% of the eligible patients of the 9 healthcare facilities). The percentage of reconciled patients within $24 \mathrm{~h}$ varied from 2.6 to $64.9 \%$ depending of the type of healthcare facilities and the assigned resources. The mean of undocumented discrepancies per patient was 1.7 (46 188) (Table 1).

Only 8 of the 9 facilities distinguished medication errors from the intentional discrepancies (no detailed data about the CHU de Grenoble). The mean of intentional discrepancies per patients was 1.0 (23 720 for 22863 patients of the 8 healthcare facilities). The mean of medication errors was 0.9 (21 320 for 22863 patients) (Table 2). All medication errors were resolved during the collaborative exchange between pharmacists and physicians. The mean time to perform the reconciliation was assessed by 10780 patients and was about $31.8 \mathrm{~min} \pm$ 1.5 min per patient (IC 95\% [31.6; 32.0]).

The year 2010 is the year of implementation of the SOP Med'Rec in a pilot facility. From 2011, it was joined by the other facilities. The increase of the percentage of patients reconciled from 2011 to 2014 is due firstly to an increase in hospitalisation in health facilities and due

Table 1 Undocumented discrepancies intercepted by reconciliation (9 healthcare facilities)

\begin{tabular}{lllllll}
\hline Year & \multicolumn{2}{l}{ Patients } & & & \multicolumn{2}{l}{ Undocumented Discrepancies } \\
\cline { 2 - 3 } & Eligible & Reconciled & $\%$ & & UD & UD/Patient \\
\hline 2010 & 1548 & 268 & 17.3 & 522 & 1.9 \\
2011 & 45686 & 3334 & 7.3 & 5639 & 1.7 \\
2012 & 47339 & 6096 & 12.9 & 8850 & 1.5 \\
2013 & 48262 & 7744 & 16.0 & 10672 & 1.4 \\
2014 & 53466 & 10005 & 18.7 & 20505 & 2.0 \\
TOTAL & 196301 & 27447 & 14.0 & 46188 & 1.7 \\
\hline
\end{tabular}


Table 2 Medication errors and intentional discrepancies intercepted by reconciliation (8 healthcare facilities)

\begin{tabular}{|c|c|c|c|c|c|c|c|}
\hline \multirow[t]{2}{*}{ Year } & \multicolumn{3}{|l|}{ Patients } & \multicolumn{2}{|c|}{ Medication Errors } & \multicolumn{2}{|c|}{ Intentional Discrepancies } \\
\hline & Eligible & Reconciled & $\%$ & $\mathrm{ME}$ & ME/Patient & $\mathrm{ID}$ & ID/Patient \\
\hline 2010 & 1548 & 268 & 17.3 & 242 & 0.9 & 280 & 1.0 \\
\hline 2011 & 34343 & 2357 & 6.9 & 1624 & 0.7 & 3758 & 1.6 \\
\hline 2012 & 35610 & 4933 & 13.9 & 3890 & 0.8 & 4448 & 0.9 \\
\hline 2013 & 35951 & 6417 & 17.8 & 5370 & 0.8 & 4996 & 0.8 \\
\hline 2014 & 40652 & 8888 & 21.9 & 10194 & 1.1 & 9899 & 1.1 \\
\hline TOTAL & 148104 & 22863 & 15.4 & 21320 & 0.9 & 23381 & 1.0 \\
\hline
\end{tabular}

secondly to an increased command of the technique of conciliation which has progressively been set up by health professionals.

\section{Discussion}

The time spent on reconciling a patient seems to be a barrier to the implementation of the reconciliation. However, this time spent is necessary as it decreases the work that would have resulted from the management of medication errors, not only at admission but also during the patients' discharge.

Before the High $5 \mathrm{~s}$ experimentation, there was no formal medication reconciliation in France. The SOP Med'Rec is a positive experience which underlined the importance of recognising medication errors at a transition point such as admission of inpatients. Indeed, with nearly one error per patient, the risks for the patients were sometimes dramatic. With awareness on this process, health professionals and patients are being sensitised to the importance of safety in medication management.

\section{Conclusions}

In several countries, the medication reconciliation process has been demonstrated to be a powerful strategy to reduce medication errors and undocumented discrepancies. This process is now being implemented in France too. At the time of writing, a national study carried out by the Ministery of Health shows that more than 363 French healthcare facilities (14.4\% of 2537 hospitals) have implemented the medication reconciliation at admission [12]. The next steps should focus on extending the process either to all stages of the transitional care or to different types of patients (other than Emergency room patients) or health sectors [13].

\section{Acknowledgements}

The authors thank Bertrice LOULIERE and the staff from the OMEDIT Aquitaine (Agence régionale de santé Nouvelle Aquitaine) for the organisation of the biannual meetings of the hospital teams and the facilitation of the exchange that have allowed to benefit from everybody's experience.

All the authors are very grateful to Elsa DUFAY, Regional Programme Coordinator for her help with translating the manuscript of this article into English.

\section{Funding}

Not applicable.

\section{Availability of data and materials}

The data that support the findings of this study are available from OMEDIT Aquitaine but restrictions apply to the availability of these data, which were used under the HAS's license for the current study, and so are not publicly available except for the synthesis. Data are however available from the authors for their own healthcare facility upon reasonable request and with permission of OMEDIT Aquitaine.

\section{Authors' contributions}

This work was carried out as part of the High 5 s project set up by the WHO in 2007 and coordinated by the WHO Collaborating Center on patient Safety. The Joint Commission in the USA, with the participation of the French Lead Technical Agency, National Authority for Health- HAS for Health partnered with OMEDIT Aquitaine and the Study Group High 5s France Medication reconciliation. DE, DS, AI \& MML analysed and interpreted the data regarding the annual Med'Rec indicators for each of the 9 healthcare facilities. DE \& DS were the major contributors in writing the manuscript. DE, MB, RMC, GA, $L A M, L K, T N, A B, D B$ have handled the implementation of the project within the health facility they manage. They ensure the formation the relevant team and validated the monthly results which were sent to the HAS and to the OMEDIT Aquitaine for control. Results were subsequently entered onto the WHO website as per the protocol of the SOP Med'Rec. Al \& MML from the Haute Autorité de Santé managed the WHO's High 5s Project bringing the methodological support to 9 involved healthcare facilities. All authors read and approved the final manuscript.

\section{Competing interests}

The authors declare that they have no competing interests.

Consent for publication

Not applicable.

Ethics approval and consent to participate

Not applicable.

\section{Publisher's Note}

Springer Nature remains neutral with regard to jurisdictional claims in published maps and institutional affiliations.

\footnotetext{
Author details

${ }^{1}$ Centre hospitalier de Lunéville, BP 30 206, 54301 Lunéville cedex, France. ${ }^{2}$ Hôpitaux universitaires de Strasbourg, 67000 Strasbourg, France. ${ }^{3}$ Centre hospitalier universitaire de Nîmes, 30029 Nîmes, France. ${ }^{4}$ Centre hospitalier de Saint-Marcellin, 38160 Saint-Marcellin, France. ${ }^{5}$ Centre hospitalier de Compiègne-Noyon, 60321 Compiègne cedex, France. ${ }^{6}$ Clinique du pont de Sèvres, 92513 Boulogne Billancourt cedex, France. ${ }^{7}$ Centre hospitalier d'Aubusson, 23200 Moutier Rozeille, France. ${ }^{8}$ Centre hospitalier universitaire de Grenoble Alpes, 38043 Grenoble Cedex 9, France. ${ }^{9}$ Centre hospitalier universitaire de Bordeaux, 33000 Bordeaux, France. ${ }^{10}$ Haute autorité de santé, 93218 Saint-Denis La Plaine Cedex, France.
} 
Received: 21 February 2017 Accepted: 8 May 2017

Published online: 23 May 2017

\section{References}

1. World Health Organization. Implementation guide. Assuring medication accuracy at transitions in care. 2014. Available at http://www.who.int/patientsafety/ implementation/solutions/high5s/h5s-guide.pdf?ua=1. Accessed Nov 052016.

2. Institute for Health Improvement. Getting Starting Kit - Assuring Medication Accuracy at Transitions in Care: Medication Reconciliation Action on Patient Safety (High 5s) - Medication Reconciliation, Volume 1-2010. Available at http://www.ihi.org. Accessed 05 Nov 2016

3. Michel P, Lathelize, Quenon JL, et al. Comparaison des 2 Enquêtes Nationales sur les Evénements Indésirables graves associés aux Soins menées en 2004 et 2009 (ENEIS). Rapport final à la DRESS (Ministère de la Santé et des Sports). Mars 2011 Available at https:/services.telesantebretagne.org/lrportal/ documents/138946/149172/ENEIS-RapportComparaison_2004-2009+finalMars2011.pdf/c167244f-a3d8-44a6-8859-4d5647e44164. Accessed 05 Nov 2016.

4. Baker GR, Norton PG. The Canadian adverse events study: the incidence of adverse events among hospitalized patients in Canada. Can Med Assoc J. 2004;170(11):1678-86,

5. Tam VC, Knowles SR, Cornish PL, et al. Frequency, type and clinical importance of medication history errors at admission to hospital : a systematic review. Can Med Assoc J. 2005;173:510-5.

6. Rennke S, Nguyen OK, Shoeb MH, et al. Hospital-initiated transitional care interventions as a patient safety strategies. A systematic review. Ann Intern Med. 2013;258:433-40

7. Dufay E, Morice S, Dony A, et al. The clinical impact of medication reconciliation on admission to a French hospital - a prospective observational study. Eur J Hosp Pharm. 2016;23:207-12. doi:10.1136/ejhpharm-2015-000745.

8. Cornish PL, Knowles SR, Marcheso R, et al. Unintended medication discrepancies at the time of hospital admission. Arch Intern Med. 2005;165:424-9.

9. Pippins JR, Gandhi TK, Hamann C, et al. Classifying and predicting errors of inpatient medication reconciliation. J Gen Intern Med. 2008;23:1414-22.

10. Quélennec B, Beretz L, Paya D, Blicklé JF, Gourieux B, Andrès E, Michel B. Potential clinical impact of medication discrepancies at hospital admission. Eur J Intern Med. 2013;24(6):530-5.

11. Gleason KM, Mc Daniel MR, Feinglass J, et al. Results of the medication at transition and clinical handoffs (MATCH) study. An analysis of medication reconciliation errors and risk factors at hospital admission. J Gen Intern Med. 2010;25:441-7.

12. Ministery of Health. La conciliation médicamenteuse : enquête sur son déploiement national. Available at http://social-sante.gouv.fr/soins-et-maladies/ qualite-des-soins-et-pratiques/qualite/la-conciliation-medicamenteuse/article/ la-conciliation-medicamenteuse-enquete-sur-son-deploiement-nationale. Accessed 25 Apr 2017.

13. Haute autorité de santé. Rapport d'expérimentation Medication Reconciliation 2015. Available at http://www.has-sante.fr/portail/upload/docs/application/pdf/ 2015-11/rapport_dexperimentation_sur_la_mise_en_oeuvre_conciliation_des_ traitements_medicamenteux_par_9_es.pdf. Accessed 05 Nov 2016.

\section{Submit your next manuscript to BioMed Central and we will help you at every step:}

- We accept pre-submission inquiries

- Our selector tool helps you to find the most relevant journal

- We provide round the clock customer support

- Convenient online submission

- Thorough peer review

- Inclusion in PubMed and all major indexing services

- Maximum visibility for your research

Submit your manuscript at www.biomedcentral.com/submit 